\title{
An Artificial Neural Network (ANN) Model for Predicting Water Absorption of Nanoclay-Epoxy Composites
}

\author{
Guillermina Capiel ${ }^{1 *}$, Arrosio Florencia ${ }^{1}$, Vera A. Alvarez ${ }^{2}$, Pablo E. Montemartini ${ }^{1}$, Juan Morán ${ }^{1}$ \\ ${ }^{1}$ Structural Composites (CET), INTEMA, National University of Mar del Plata, Mar del Plata, Argentina \\ ${ }^{2}$ Composite Materials (COMP), INTEMA, National University of Mar del Plata, Mar del Plata, Argentina \\ Email: *guillermina.capiel@fi.mdp.edu.ar
}

How to cite this paper: Capiel, G., Florencia, A., Alvarez, V.A., Montemartini, P.E. and Morán, J. (2019) An Artificial Neural Network (ANN) Model for Predicting Water Absorption of Nanoclay-Epoxy Composites. Journal of Materials Science and Chemical Engineering, 7, 87-97. https://doi.org/10.4236/msce.2019.78010

Received: June 10, 2019

Accepted: August 27, 2019

Published: August 30, 2019

Copyright $\odot 2019$ by author(s) and Scientific Research Publishing Inc. This work is licensed under the Creative Commons Attribution International License (CC BY 4.0).

http://creativecommons.org/licenses/by/4.0/

(c) $\underset{\mathrm{EY}}{\mathrm{C}}$ Open Access

\begin{abstract}
Glass fiber reinforced epoxy (GFRE) composite materials are prone to suffer from water absorption due to their heterogeneous structure. The main process governing water absorption is diffusion of water molecules through the epoxy matrix. However, hydrolytic degradation may also take place during components service life specially due high temperatures. In order to mitigate the effects of the water diffusive processes in the deterioration of in-service behavior of epoxy matrix composites, the use of chemically modified nanoclays as an additive has been proposed and studied in previous works [1]. In this work, an Artificial Neural Network (ANN) model was developed for better understanding and predicting the influence of modified and unmodified bentonite addition on the water absorption behavior of epoxy-anhydride systems. An excellent correlation between model and experimental data was found. The ANN model allowed the identification of critical points like the precise temperature at which a particular system's water uptake goes beyond a predefined threshold, or which system will resist an immersion longer than a particular time.
\end{abstract}

\section{Keywords}

Artificial Neural Networks, Epoxy-Anhydride, Clay Nanocomposites, Water Absorption

\section{Introduction}

Glass fiber reinforced epoxy (GFRE) composite materials are prone to suffer from water absorption due to their heterogeneous structure. The main process governing water absorption is diffusion of water molecules through the epoxy 
matrix. However, depending on the polymer matrix and the operation temperature, other mechanisms could be involved and water absorption process may lead to material degradation. This process could modify the chemical structure [2] [3] as well as the thermal and mechanical behavior of the matrix [4] [5] and the interface [6] [7]. Thus, water absorption in polymer matrix composite materials is a phenomenon that has a high industrial interest because environmental conditions influence the integrity of facilities during operation reducing its service life. The oil industry regularly uses composite pipes made of glass fiber reinforced (anhydride) epoxy (GFRE). GFRE has many advantages specially in injection lines in mature fields where transported fluids are aqueous based and contain a high percentage of salts, which restricts the use of metallic materials due to the impact of corrosion processes. However, the operating temperature may reach values that activate polymeric matrix chemical degradation processes with fatal consequences over relatively short time periods (1 to 5 years) [7].

When composite materials based in polymer matrices of low hydrophilicity but containing hydrolysable groups are exposed to humid and high temperature conditions, failure is a consequence of matrix hydrolysis. Water absorption behavior is then the result of simultaneous mechanisms: diffusion and chemical reaction.

The water diffusion process in thermoset polymers rarely presents the classic behavior predicted by Fick's Law. The description of this process from gravimetric monitoring data allows observing different stages. An early linear behavior is observed in the mass uptake as a function of the square root of elapsed time, which conforms to the classic model. A second stage with a decreasing slope or a pseudo-equilibrium behavior can be observed afterwards. This second step is followed by a further increase in water content that may either reach a second equilibrium or increase indefinitely during the studied time span [8].

In the literature, different models that attempt to explain this phenomenon are presented. One of the most commonly used models is the Langmuir model proposed by Carter and Kibler [9], in which the water molecules absorbed by the material may be distinguished into two classes: linked and non-linked molecules. Linked water molecules refer to water linked to highly hydrophilic sites in the epoxy matrix by low-energy hydrogen bonds. Non-linked water molecules refer to water molecules that may be freely transported within the epoxy matrix. For each case, there is a probability that water molecules transform from one state to another as explained by Carter and Kibler [9].

For epoxy-anhydride matrices, the hydrolytic degradation reaction plays an important role since the material contains hydrolysable groups [10]. With increasing temperature, hydrolysis is enhanced and consequently is the degradation of the composite. The hydrolysis changes the polymer structure decreasing its cross-linking density and forming new polar groups (alcohols and carboxyl acids). These changes also affect the water diffusion behavior. Both mechanisms are coupled. In addition, there are other consequences associated with the hydrolytic degradation. When the chemical reaction advances, small molecular 
weight species resulting from the hydrolytic process may lead to osmotic cracking. This extremely complex behavior makes it more difficult to theoretically model the coupled phenomena for predicting service life.

In order to mitigate the effects of the water diffusive processes in the deterioration of in-service behavior of epoxy matrix composites, the use of chemically modified nanoclays as an additive has been proposed. Many authors have found a considerably improvement in barrier properties of epoxy systems containing small amounts of clay as reinforcement [11]-[18]. The effect on water absorption behavior of adding bentonite and chemically modified bentonite to an epoxyanhydride system was studied in a previous work [1]. It was found that epoxyanhydride systems containing small amounts of chemically modified bentonite show higher water resistance than bentonite-epoxy composites and neat matrix. Moreover, the addition of 3 wt. \% modified bentonite slows down the degradation process allowing the extension of the service life up to twenty years.

The aim of this work is to create an Artificial Neural Network (ANN) model to understand and to predict the influence of modified and unmodified bentonite addition on the water absorption behavior of epoxy-anhydride systems for its use in fiber-reinforced composites.

For this purpose, ANN based modelling is proposed as a different and very accurate approach for reproducing the physical behavior of epoxy resins when immersed in water. ANNs are an interesting class of computing programs that mimic the intelligence of biological cognitive systems. The individual computing units of these programs are called neurons and consist on a processing component that receive different inputs and deliver an output value by means of a weighted integration and a sigmoid-shaped transfer function. Training consists on calculating the proper interconnection weights and biases so that the network can associate the inputs with their corresponding outputs with minimum global error.

The ANN modeling approach is very suitable for modelling nonlinear multivariate interrelationships on noisy systems [19] [20] and has been used in the recent years by many researchers to model and predict properties of several materials [21]-[26]. This modeling approach can take advantage of the learning ability of ANNs, as they can build a model directly from experimental results without exactly knowing the underlying physics. Another important feature of ANNs is their good response from incomplete or noisy data, thus allowing a fair understanding of new systems or novel cases [21] [27] [28].

\section{Experimental}

\subsection{Materials and Methods}

The materials studied in this work were prepared using an epoxy resin based on diglycidyl ether of bisphenol A (DGEBA, DER 383, Dow Chemical Co.) and a methyltetrahydroftalic anhydride (LINDRIDE 36K, Lindau Chemicals, Inc.) as a curing agent. In order to obtain the epoxy clay composites, a commercially 
available bentonite clay was used (provided by Minarmco S.A., Argentina). In addition, a tributylhexadecylphosphonium bromide (Sigma Aldrich) based modification was performed in our labs. Details about bentonite chemical modification can be found in reference [29]. Samples of epoxy-anhydride, epoxyanhydride containing 1 and $3 \mathrm{wt} \%$ bentonite and epoxy-anhydride containing 1 and 3 wt.\% modified bentonite were prepared. Hereinafter, these systems are denoted as B0, B1, B3, BM1 and BM3 respectively. The epoxy-anhydride system was prepared using stoichiometric ratios of the epoxy resin and the hardener; details about samples preparation are reported in reference [1].

\subsection{Water Absorption}

In order to study water uptake, rectangular samples of B0, B1, B3, BM1 and BM3 $\left(55 \times 12 \times 1 \mathrm{~mm}^{3}\right)$ were immersed in distilled water at three different temperatures: $22^{\circ} \mathrm{C}, 80^{\circ} \mathrm{C}$ and $93^{\circ} \mathrm{C}$. The samples were removed from water, dried with a tissue paper, weighed in an analytical balance, and the returned into water at regular intervals of times. The water uptake was determined using the following expression

$$
\text { Mass change }(\%)=\frac{m_{t}-m_{i}}{m_{i}} \times 100
$$

where $m_{t}$ is the sample mass at time $t$, and $m_{i}$ is the initial sample mass. Epoxy clay composites were studied for long exposure times (900 days or $7.810^{7}$ s).

\subsection{Model Description}

In this study two different ANNs were implemented, one for the commercial bentonite system and another for the chemically modified bentonite, both having the same identical architecture. The ANNs trained in this study were fully connected feed-forward networks with two layers of hidden neurons. A two hidden-layers architecture was selected to better represent the nonlinear nature of the problem. The input layer consisted of three input nodes representing the clay content, temperature and immersion time and the output layer consisted of one output node representing the water uptake. Therefore, the model represents a mapping associating these three factors with the water absorption of the reinforced epoxy resin. The optimal number of neurons in each hidden layer was selected by sequentially adding new neurons and minimizing the overall fitting error and correlation coefficient. As a result, five hidden neurons in each hidden-layer were used. A Levenberg-Marquardt Back-Propagation (LMBP) supervised training algorithm was used, as it is one of the fastest existing backpropagation algorithms and is highly recommended as a first-choice supervised algorithm, although it needs more memory than other available algorithms.

A total of 60 data sets containing more than 4600 points were used in this study (around 2300 for each type of clay). Each data point consisted of the following parameters: a) clay content (\%); b) immersion time (s); c) temperature 
(C); d) water absorption (\%). The first three parameters were mapped to the input neurons and the remaining parameter was mapped to the output neuron. Available experimental data was randomly distributed into training, validation and testing sets. Following literature recommendations, $70 \%$ of the data was used in the network training process, $20 \%$ in network validation and the remaining $10 \%$ in testing. As result, a correlation coefficient greater than 0.96 was obtained. The trained neural network architectures were applicable within the experimental range.

In order to prevent distortion of the significance of each factor, input data was normalized into $[-1,1]$ dimensionless interval. Finally, the ANN results (output layer) were mapped by the inverse linear operation to the output (water absorption) layers (denormalization operation).

In order to avoid overfitting and improve generalization ability of the trained ANNs, two strategies were simultaneously applied. The first simple method consisted in averaging the results of multiple ANNs trained with the same experimental data sets, but with different random data partitioning (training, validating and testing). The second method is called regularization and consisted in continuously modifying the performance function during network training and thus modernizing calculated weights and biases.

\section{Results and Discussion}

The experimental data obtained from gravimetric tests for the five systems studied at different temperatures are shown in Figures 1(a)-(e). Absorption tests results are presented as a function of the square root of immersion time and sample depth $\left(\mathrm{t}^{0.5} / \mathrm{e}[=] \mathrm{min}^{0.5} / \mathrm{mm}\right)$. The trained ANNs were used to fit experimental values and to predict interpolated values. The corresponding modeled results are also presented in Figures 1(a)-(e). As expected, ANNs have an exceptional ability to fit multivariate nonlinear systems. A very accurate fitting was obtained.

The completely trained ANN can be further used to build full Temperature-Time-\%Absorption maps for the five systems analyzed (Figures 2(a)-(e)). This allows comparing the global behavior of the systems under novel and unstudied circumstances.

The epoxy-anhydride water uptake behavior has been studied previously in literature and its hygrothermal aging is described as the result of coupled mechanisms: diffusion and hydrolysis [10] [30]. Water enters into the polymer by diffusion and then it may react with the ester groups that are present in the epoxy-anhydride network. Each hydrolysis event is a chain-scission process and consequently, as the reaction goes on, species of lower molecular weight appear within the network. These species are alcohols and carboxyl acids resulting from the hydrolysis. However, when the low molecular weight species concentration exceeds its solubility in the epoxy network they demix forming domains (or vacuoles) with a high concentration of small species. It induces a steep increase 


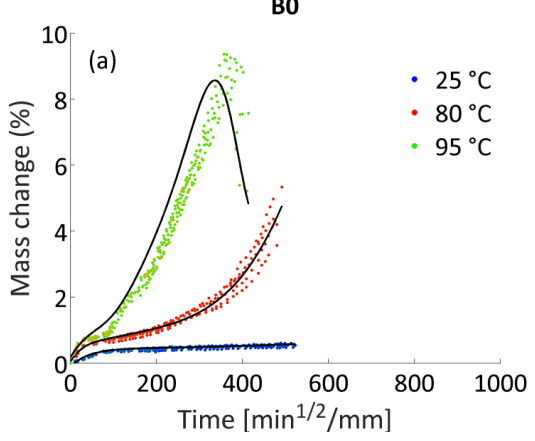

B1

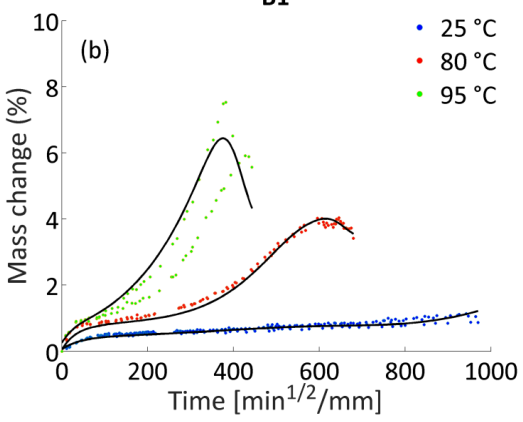

BM1

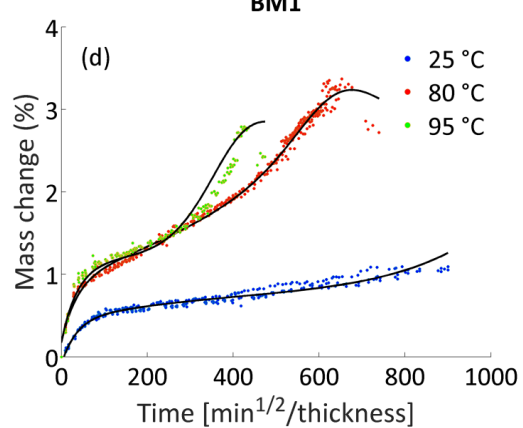

B3

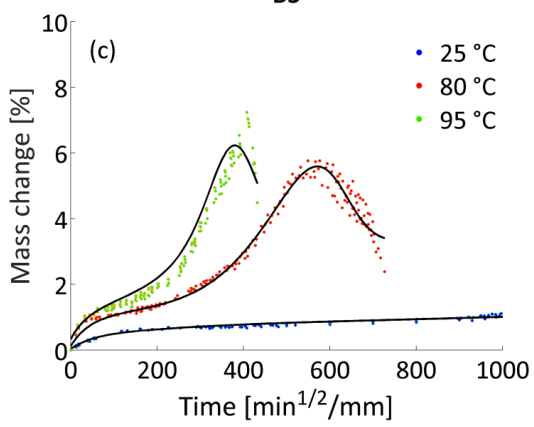

BM3

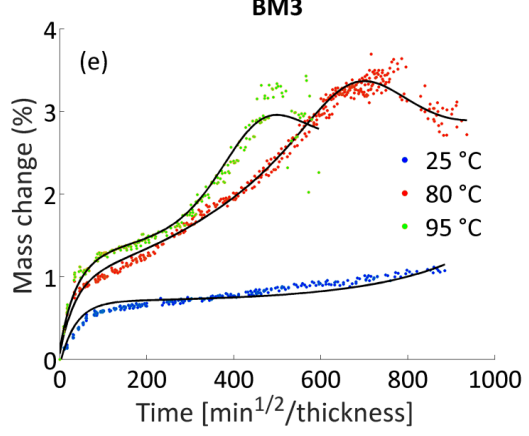

Figure 1. Gravimetric data (dots) and model (line) for water absorption behavior of epoxy-anhydride composites immersed in water at $22^{\circ} \mathrm{C}, 80^{\circ} \mathrm{C}$ and $93^{\circ} \mathrm{C}$ : (a) B0; (b) B1; (c) B3; (d) BM1; (e) BM3.

in water intake originated by osmotic pressure until these domains collapses and the subsequent leaching of low molecular weight species takes place. The last step is observed in gravimetric data as a drastic decrease in material mass.

The ANN model allows identifying critical points like the precise temperature at which a particular system's water uptake goes beyond a predefined threshold, or which system will resist an immersion longer than a particular time. In order to explain water absorption behavior, the whole time-temperature-absorption maps were analyzed and the point of maximum absorption was indentified. The main critical point (P1) is the absorption maximum, which occurs before mass drops down ( $\mathrm{d} a b s / \mathrm{d} t=0)$. Figure 3 shows P1 mass uptake vs. time in the whole temperature range. 


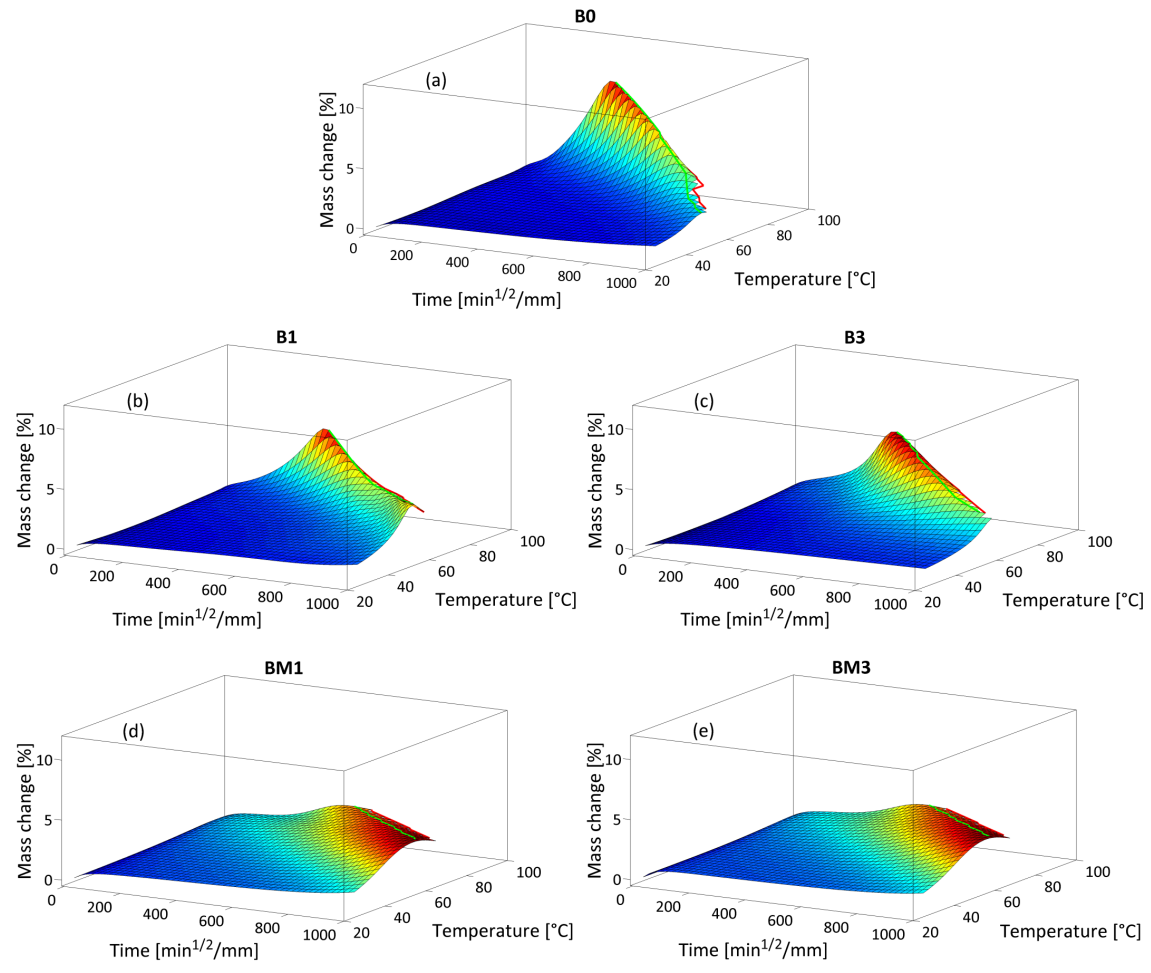

Figure 2. Temperature-time-\%absorption maps for the five systems analyzed: (a) B0; (b) B1; (c) B3; (d) BM1; (e) BM3.

Considering time-temperature-absorption maps for modified and unmodified bentonite samples a first observation can be highlighted. Although ANN model was trained using 25,80 y $93^{\circ} \mathrm{C}$ experimental data, within the time frame analyzed (900 days - $1 \mathrm{~mm}$ thickness) a sudden weight reduction can be observed above $55^{\circ} \mathrm{C}-65^{\circ} \mathrm{C}$. This model prediction agrees with the limit operation temperature recommended for glass fiber epoxy-anhydride pipes.

Figure 3 show time and mass increase of the critical point (P1) which determine the catastrophic degradation generated by the sudden crack growth produced by osmotic pressure $(\mathrm{d} a b s / \mathrm{d} t=0)$. As it was pointed earlier, in the time-frame studied the critical point $\mathrm{P} 1$ exists above $55^{\circ} \mathrm{C}-65^{\circ} \mathrm{C}$, below this temperature hydrolysis is slow enough to be neglected. Figure 3 clearly shows the way in which time-to-catastrophic-failure changes with temperature. The transition points predicted by ANN for different systems can be adequately fitted by a linear first order equation. A linear relationship between time-to-failure and temperature is common to modified and unmodified bentonite samples as well as neat epoxy samples. Moreover, the slope is virtually constant (13.55 \pm 0.21 ) even though $B M$ samples show extended times. The fact that the B, BM and neat samples present the same slope is consistent with interaction energy (Hs) reported previously [1]. Since water-network interaction is not modified by adding neither bentonite nor modified bentonite, the time needed to reach the pressure required for instable crack propagation does not change either. The extension in time shown by TBHP-bentonite samples was explained in a previous 


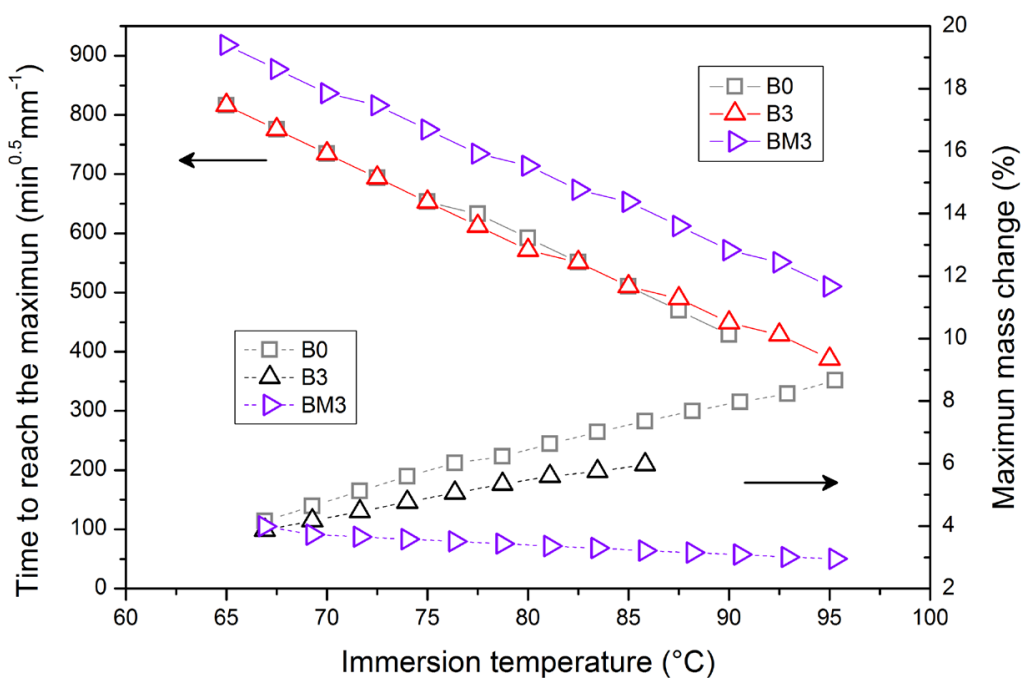

Figure 3. Time required to reach the maximum mass change (\%) and maximum mass change (\%) as a function of immersion temperature.

work [1], the nano-scale morphology obtained in TBHP-bentonite composites decreases the concentration of water molecules in contact with network backbone, which was confirmed by a smoother Tg versus mass uptake decrease reported in previous publications [1]. The decrease in water-reactive site concentration, produces a reduction on the hydrolysis rate, and extends the service life.

Figure 3 shows stronger differences in mass uptake at the critical point (P1). While $\mathrm{BM}$ samples mass uptake remains practically constant between $60^{\circ} \mathrm{C}$ and $95^{\circ} \mathrm{C}$, neat samples (B0) mass uptake grow considerably. ANN prediction allows explaining how modified bentonite extends service life according the epoxyanhydride failure model previously described. Organic modifier would locally increase the miscibility of low molecular weight species. Then, a lower number of vacuoles are formed decreasing the amount of water intake due to osmotic pressure. However, each vacuole will become a propagating crack once the internal pressure reaches the critical value. A lower vacuoles number is not only responsible for the decrease in mass uptake but also explain the milder falls down after maximum. Figure 4 shows the mass uptake rate after failure, BM3 present a 50 to 70 times lower rate than $\mathrm{B} 0$.

\section{Conclusions}

The present study reaffirms that ANN methodology can be used to simulate the problems that are not easily quantifiable via linear operations and when there is a lack of subjacent theoretical model to explain the behavior of the system.

Full time-temperature-absorption maps were built based on model results which allowed an excellent prediction of the system's behavior over non-tested conditions. The model also allowed identifying critical operation points like the temperature at which the water uptake goes beyond a predefined threshold, or which system will resist an immersion longer than a particular time. 


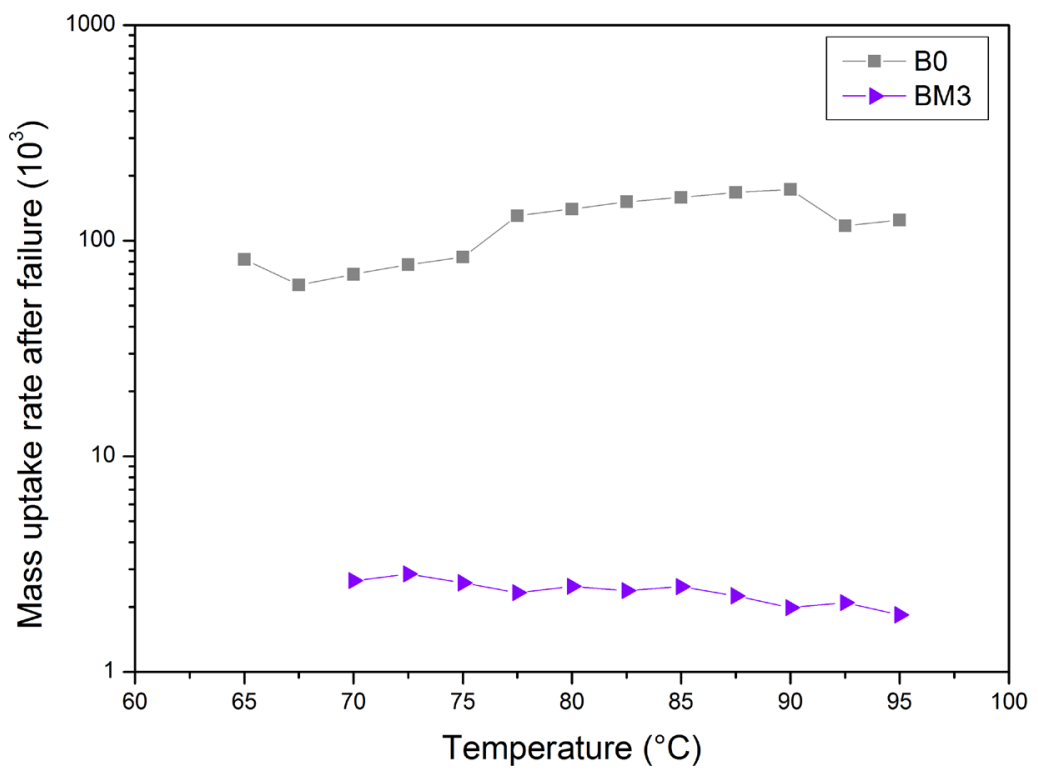

Figure 4. Mass uptake rate after failure $\left(10^{3}\right)$ as a function of immersion temperature for materials $\mathrm{B} 0$ and $\mathrm{BM} 3$.

Predictions allow understanding how the modification of bentonite could delay hydrolisys-related failure of composites.

The information extracted from the use of the developed model will be of critical importance to better application of glass fiber reinforced epoxy composite materials in industrial applications.

\section{Acknowledgements}

The authors acknowledge support from FONARSEC (Agencia Nacional de Promoción Científica y Tecnológica), CONICET and Universidad Nacional de Mar del Plata.

\section{Conflicts of Interest}

The authors declare no conflicts of interest regarding the publication of this paper.

\section{References}

[1] Capiel, G., Uicich, J., Alvarez, V. and Montemartini, P. (2017) Improving the Water Resistance of Epoxy-Anhydride Matrices by the Incorporation of Bentonite. Polymers for Advanced Technologies, 28, 886-896.

[2] Antoon, M.K. and Koenig, J.L. (1981) Irreversible Effects of Moisture on the Epoxy Matrix in Glass-Reinforced Composites. Journal of Polymer Science: Polymer Physics Edition, 19, 197-212. https://doi.org/10.1002/pol.1981.180190202

[3] Richaud, E., Gilormini, P., Coquillat, M. and Verdu, J. (2014) Crosslink Density Changes during the Hydrolysis of Tridimensional Polyesters. Macromolecular Theory and Simulations, 23, 320-330. https://doi.org/10.1002/mats.201300143

[4] Alessi, S., Conduruta, D., Pitarresi, G., Dispenza, C. and Spadaro, G. (2011) Accele- 
rated Ageing Due to Moisture Absorption of Thermally Cured Epoxy Resin/Polyethersulphone Blends. Thermal, Mechanical and Morphological Behaviour. Polymer Degradation and Stability, 96, 642-648.

https://doi.org/10.1016/j.polymdegradstab.2010.12.027

[5] Ellyin, F. and Maser, R. (2004) Environmental Effects on the Mechanical Properties of Glass-Fiber Epoxy Composite Tubular Specimens. Composites Science and Technology, 64, 1863-1874. https://doi.org/10.1016/j.compscitech.2004.01.017

[6] Stocchi, A., Pellicano, A., Rossi, J.P., Bernal, C. and Montemartini, P. (2006) Physical and Water Aging of Glass Fiber-Reinforced Plastic Pipes. Composite Interfaces, 13, 685-697. https://doi.org/10.1163/156855406779366831

[7] Rodríguez, E.S., Alvarez, V.A. and Montemartini, P.E. (2013) Failure Analysis of a GFRP Pipe for Oil Transport. Engineering Failure Analysis, 28, 16-24.

https://doi.org/10.1016/j.engfailanal.2012.07.025

[8] Pascault, J., Sautereau, H., Verdu, J. and Williams, R.J.J. (2002) Thermosetting Polymers. CRC Press, New York. https://doi.org/10.1201/9780203908402

[9] Carter, H.G. and Kibler, K.G. (1978) Langmuir-Type Model for Anomalous Moisture Diffusion in Composite Resins. Journal of Composite Materials, 12, 118-131. https://doi.org/10.1177/002199837801200201

[10] El Yagoubi, J., Lubineau, G., Roger, F. and Verdu, J. (2012) A Fully Coupled Diffusion-Reaction Scheme for Moisture Sorption-Desorption in an Anhydride-Cured Epoxy Resin. Polymer, 53, 5582-5595. https://doi.org/10.1016/j.polymer.2012.09.037

[11] Becker, O., Varley, R.J. and Simon, G.P. (2004) Thermal Stability and Water Uptake of High Performance Epoxy Layered Silicate Nanocomposites. European Polymer Journal, 40, 187-195. https://doi.org/10.1016/j.eurpolymj.2003.09.008

[12] Mohan, T.P., Kumar, M.R. and Velmurugan, R. (2006) Mechanical and Barrier Properties of Epoxy Polymer Filled with Nanolayered Silicate Clay Particles. Journal of Materials Science, 41, 2929-2937. https://doi.org/10.1007/s10853-006-5164-4

[13] Glaskova, T. and Aniskevich, A. (2009) Moisture Absorption by Epoxy/Montmorillonite Nanocomposite. Composites Science and Technology, 69, 2711-2715. https://doi.org/10.1016/j.compscitech.2009.08.013

[14] Zhu, H.-G., Leung, C.K.Y., Kim, J.-K. and Liu, M.-Y. (2011) Degradation of Glass Fiber-Reinforced Plastic Composites Containing Nanoclay in Alkaline Environment. Journal of Composite Materials, 45, 2147-2156. https://doi.org/10.1177/0021998311401064

[15] Zhu, H.-G., Leung, C.K.Y., Kim, J.-K. and Liu, M.-Y. (2012) Tensile Properties Degradation of GFRP Composites Containing Nanoclay in Three Different Environments. Journal of Composite Materials, 46, 2179-2192. https://doi.org/10.1177/0021998311430424

[16] Alamri, H. and Low, I.M. (2013) Effect of Water Absorption on the Mechanical Properties of Nanoclay Filled Recycled Cellulose Fibre Reinforced Epoxy Hybrid Nanocomposites. Composites Part A: Applied Science and Manufacturing, 44, 23-31. https://doi.org/10.1016/j.compositesa.2012.08.026

[17] Al-Qadhi, M., Merah, N. and Gasem, Z.M. (2013) Mechanical Properties and Water Uptake of Epoxy-Clay Nanocomposites Containing Different Clay Loadings. Journal of Materials Science, 48, 3798-3804. https://doi.org/10.1007/s10853-013-7180-5

[18] Rull, N., Ollier, R., Francucci, G., Rodriguez, E.S. and Alvarez, V.A. (2015) Effect of the Addition of Nanoclays on the Water Absorption and Mechanical Properties of 
Glass Fiber/Up Resin Composites. Journal of Composite Materials, 49, 1629-1637. https://doi.org/10.1177/0021998314538869

[19] Sobhani, J., Najimi, M., Pourkhorshidi, A.R. and Parhizkar, T. (2010) Prediction of the Compressive Strength of No-Slump Concrete: A Comparative Study of Regression, Neural Network and ANFIS Models. Construction and Building Materials, 24, 709-718. https://doi.org/10.1016/j.conbuildmat.2009.10.037

[20] Hagan, M.T., Demuth, H.B. and Beale, M.H. (1996) Neural Network Design. PWS Publishing, Boston, MA, 734.

[21] Najigivi, A., Khaloo, A., Iraji Zad, A. and Abdul Rashid, S. (2013) An Artificial Neural Networks Model for Predicting Permeability Properties of Nano Silica-Rice Husk Ash Ternary Blended Concrete. International Journal of Concrete Structures and Materials, 7, 225-238. https://doi.org/10.1007/s40069-013-0038-z

[22] Golestanian, H. and Poursina, M. (2009) Neural Network Analysis Application to Permeability Determination of Fiberglass and Carbon Preforms. Chinese Journal of Polymer Science, 27, 221-229. https://doi.org/10.1142/S0256767909003856

[23] Sablani, S.S. and Rahman, M.S. (2003) Using Neural Networks to Predict Thermal Conductivity of Food as a Function of Moisture Content, Temperature and Apparent Porosity. Food Research International, 36, 617-623.

[24] Kasperkiewicz, J. and Dubrawskp, A. (1996) HPC Strength Prediction Using Artificial Neural Network. Journal of Computing in Civil Engineering, 9, 279-284. https://doi.org/10.1061/(ASCE)0887-3801(1995)9:4(279)

[25] Čapková, P., Pospíšil, M., Valášková, M., et al. (2006) Structure of Montmorillonite Cointercalated with Stearic Acid and Octadecylamine: Modeling, Diffraction, IR Spectroscopy. Journal of Colloid and Interface Science, 300, 264-269.

[26] Nazari, A., Sedghi, A. and Didehvar, N. (2012) Modeling Impact Resistance of Aluminum-Epoxy-Laminated Composites by Artificial Neural Networks. Journal of Composite Materials, 46, 1593-1605. https://doi.org/10.1177/0021998311421222

[27] Topçu, İ.B. and Sarıdemir, M. (2007) Prediction of Properties of Waste AAC Aggregate Concrete Using Artificial Neural Network. Computational Materials Science, 41, 117-125. https://doi.org/10.1016/j.commatsci.2007.03.010

[28] Topçu, I.B. and Saridemir, M. (2008) Prediction of Rubberized Mortar Properties Using Artificial Neural Network and Fuzzy Logic. Journal of Materials Processing Technology, 199, 108-118. https://doi.org/10.1016/j.jmatprotec.2007.08.042

[29] Penoff, M.E., Lanfranconi, M., Alvarez, V.A. and Ollier, R. (2015) Curing Kinetics of Epoxy/Alkyl Phosphonium Modified Nanoclay Composites for High Performance Applications. Thermochimica Acta, 608, 20-29.

https://doi.org/10.1016/j.tca.2015.04.008

[30] Colin, X. and Verdu, J. (2014) Aging of Organic Matrix Composite Materials. Wiley Encyclopedia of Composites. In: Davies, P. and Rajapakse, Y., Eds., Durability of Composites in a Marine Environment, Springer, Dordrecht, 47-114. 